\title{
Design of Modular Power Management and Attitude Control Subsystems for a Microsatellite
}

\author{
Anwar Ali $\mathbb{D}^{1}{ }^{1}$ Shoaib Ahmed Khan, ${ }^{2}$ M. Usman Khan, ${ }^{2}$ Haider Ali $\mathbb{D}^{1},{ }^{1}$ M. Rizwan Mughal, ${ }^{3,4}$ \\ and Jaan Praks ${ }^{4}$ \\ ${ }^{1}$ Electrical Technology Department, University of Technology (UoT), Nowshera, Pakistan \\ ${ }^{2}$ National University of Computer \& Emerging Sciences Peshawar Campus, Pakistan \\ ${ }^{3}$ Department of Electrical Engineering, Institute of Space Technology, Islamabad, Pakistan \\ ${ }^{4}$ Department of Electronics and Nanoengineering, School of Electrical Engineering, Aalto University, FI-00076 AALTO, \\ 02150 Espoo, Finland
}

Correspondence should be addressed to Anwar Ali; safi2000pk@gmail.com

Received 16 February 2018; Accepted 29 August 2018; Published 17 December 2018

Academic Editor: Jeremy Straub

Copyright (c) 2018 Anwar Ali et al. This is an open access article distributed under the Creative Commons Attribution License, which permits unrestricted use, distribution, and reproduction in any medium, provided the original work is properly cited.

\begin{abstract}
The Electric Power System (EPS) and attitude control system (ACS) are the essential components of any satellite. EPS and ACS efficiency and compactness are substantial for the proper operation and performance of the satellite's entire mission life. So, realizing the significance of EPS and ACS subsystems for any satellite, they have been assimilated and developed in modular forms focusing on efficiency and compactness. The EPS is comprised of three modules called the solar panel module (SPM), power conditioning module (PCM), and power distribution module (PDM) while the ACS has an embedded magnetorquer coil. For compactness and miniaturization purposes, the magnetorquer coil is embedded inside the SPM. The components used are commercial off-the-shelf (COTS) components emphasizing on their power efficiency, small dimensions, and weight. Latch-up protection systems have been designed and analyzed for CMOS-based COTS components, in order to make them suitable for space radioactive environment. The main design features are modularity, redundancy, power efficiency, and to avoid single component failure. The modular development of the EPS and ACS helps to reuse them for future missions, and as a result, the overall budget, development, and testing time and cost are reduced. A specific satellite mission can be achieved by reassembling the required subsystems.
\end{abstract}

\section{Introduction}

Many universities around the world are working on various projects of small satellites [1-6]. These satellites are classified into various categories on the basis of their mass and dimensions, i.e., pico, nano, and micro. The main driving force for the development of small satellites is their low budget requirement, short development time, low mass and size, new technology, and because they provide more costeffective and reliable access to space [7]. Small satellites are designed for low earth orbit (LEO); therefore, launching cost is also comparatively low. Small satellites can provide an ideal testbed to innovative technologies (e.g., hardware and software) which can be further used in large and expensive space missions. University satellite programs teach students the whole lifecycle of a satellite on a real situation and develop their capabilities in the space sector. Due to mentioned facts, small satellites have been considered a vital technology by many space mission experts.

The number of student-built small satellites is rapidly growing, specifically in Europe and in North America. The list of the number of universities working on satellite projects is too long, and it is impossible to mention all of them here. But some of the universities that are particularly moving the small satellite industry forward and working on very nice projects are mentioned here. From the United States of America, the significant contribution is from Cal Poly and Stanford University, University of Michigan, University of Texas, Air Force Academy, Massachusetts Institute of Technology, Colorado University Boulder, Santa Clara University, 


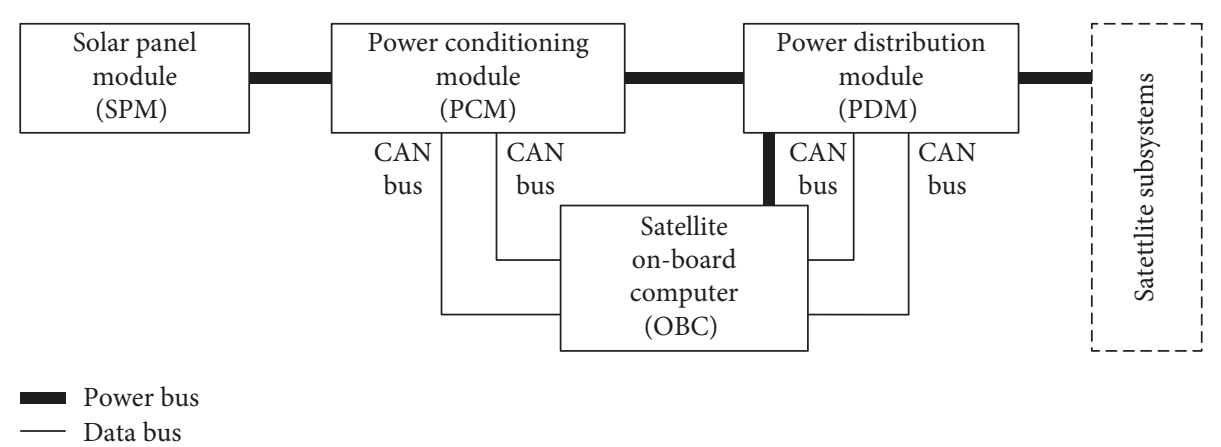

FIGURE 1: Block diagram of EPS subsystems.

Arizona State University, and many more [8, 9]. From Europe, the contribution worth mentioning is from the Swedish Institute of Space Physics, Aalborg University, Technical University of Denmark, Norwegian University of Technology and Science (NTNU), University of Wurzburg, Aachen University of Applied Sciences, Delft University of Technology, Swiss Federal Institute of Technology (EPFL), Budapest University of Technology and Economics, University of Montpellier II, Warsaw University of Technology, Sapienza University of Technology, University of Vigo, Polytechnic University of Turin, Berlin Technical University, the Space Research Centre of Polish Academy of Sciences, and a lot of other institutions. In Asia, the main contributing universities are from Japan, China, South Korea, Singapore, and India [9].

Keeping in view the significance of small satellites, the Pakistan National Space and Upper Atmospheric Research Corporation (SUPARCO) has framed the Pakistan National Student Satellite (PNSS) program [10]. This program will involve the local universities and industry in collaboration with SUPARCO for the development and launching of small satellites into space. In this program, PNSS-1 is the first small satellite that will be deployed into space. Universities are part of the designing process of the satellite. The main aim of this work is to design and analyze modular EPS and ACS for the PNSS-1 satellite which has a size of $50 \mathrm{~cm}^{3}$ with $50 \mathrm{~kg}$ mass and one-year service life [11].

The EPS is responsible for fulfilling the power needs of the entire satellite. The paper proposes a novel approach to design and elegantly interconnect the EPS subsystems of a modular small satellite [12]. In the proposed modular design technique, the EPS is divided into small modules that are designed and developed independently and are attached together to attain the intended results. The major subsystems of the EPS are the solar panel subsystem, conversion of the solar panel power to the power distribution bus (PDB) level subsystem, and conversion of the unregulated PDB voltage level into various low voltage levels required for operation of the satellite subsystem components. The EPS also has a subsystem to store the excess generated power into onboard batteries and extract power from them during satellite night and solar eclipses. Different housekeeping sensors are embedded in the EPS subsystems to monitor and ensure the proper operation of the complete satellite. To perform all the abovementioned tasks, the whole EPS is subdivided into three modules called the solar panel module (SPM), power conditioning module (PCM), and power distribution module (PDM). This modular design approach is not only cost effective because the design, development, and testing costs are shared among these modules but also time saving because of the parallel development approach rather than the classical serial one [13-16]. In addition, the modular design extensively results in overall cost reduction because the cost is shared among many modules that can be used several times in other missions.

Each module offers standardized power and data interfaces. A block diagram of the EPS subsystems is depicted in Figure 1.

The SPM is responsible for the power generation of PNSS-1. Four solar panels are attached on the outside periphery of the satellite accountable for power generation. One solar panel generates sufficient power to meet the power needs of the complete satellite. The SPM output power is not constant and has variable voltage and current levels depending on solar power density and environment factors. The power conditioning module (PCM) converts this unstable SPM output voltage to a stable PDB voltage level. The PCM operates the solar panels at its maximum power point (MPP) to harvest maximum power. For this purpose, the PCM has four Maximum Power Point Tracking- (MPPT-) based converters. Each converter is connected to four solar panels on the input side and regulates the battery charge and discharge on the MPPT scheme on the output side. The functional requirements of the PCM are to generate the PDB for the spacecraft at $28 \mathrm{~V} \pm 6 \mathrm{~V}$ from raw power available from four body-mounted solar panels. The input voltage of the PCM may vary from $40 \mathrm{~V}$ to $80 \mathrm{~V}$. The PCM is connected with the satellite onboard computer (OBC) through redundant CAN buses. It has an interface with all of the power sources (i.e., solar panels and battery) and outputs the PDB to the power distribution module (PDM). The PDM converts the PDB voltage level into lower specific voltage levels and distributes them to loads as per their requirements [17]. The PDM also has the EMI filtration as well as different protections on each distribution line in order to limit the electromagnetic noise on the main bus and prevent fault propagation. The ON/OFF switching of all switchable loads is also implemented inside the PDM. These switches are controllable through telecommands. The complete design 
of the specific module is discussed in the respective section of this paper, in detail.

The ACS of the PNSS- 1 is responsible for attitude control as is obvious from its name. The ACS is responsible for orienting the satellite solar panels for harvesting maximum solar power and the satellite antenna toward ground station antennas. For the attitude control of small satellites, three types of systems are normally used, i.e., permanent magnet, reaction wheel, and magnetic rods. All the three systems have their pros and cons. For example, the permanent magnet is inexpensive, but its weight and pointing accuracy makes it incompatible with small satellites. Reaction wheels and magnetic rods are more precise, but their high price, greater weight, and large size are unacceptable for small satellites. In this paper, an innovative concept of an embedded magnetorquer coil is presented for the attitude control of small satellites. The magnetorquer coil comprises four subcoils embedded inside the four internal layers of an eight-layer PCB of the SPM module. This innovative design not only reduces cost and size of the magnetorquer unit but also results in an almost weightless system.

The paper is organized according to the following sequence. Section 1 provides the EPS introduction and Section 2 describes the design and analysis of the SPM subsystem. Section 3 discusses the design description of PCM subsystems according to general constraints and explains in detail the design and simulations of a wide range input MPPT-based buck converter. Section 4 describes the design details of the PDM, while the last, Section 5, discusses the results and conclusions.

\section{Solar Panel Module}

Selecting the correct power ratings for the SPM is the most important aspect of the photovoltaic (PV) system design for a microsatellite. The inappropriate string size will result in many problems. Choosing a small string size will result in small efficiency. Selecting a large string size will damage the converter and the associated equipment [18]. Solar cells can be connected in any fashion, i.e., series or parallel. Series connections increase the voltage with the current kept constant while parallel connections increase the current of the string with the voltage remaining constant. Calculating the string size, the relationship between ambient temperature and string voltage must be taken into consideration. Ambient temperature has adverse effect on PV array voltage output. Low temperatures result in increases to output voltage while high temperatures decrease string voltage. Proper and accurate power analysis is essential to compute the power ratings for efficient SPM design [19].

Triple-junction GaAs solar cells are selected for the solar panel design of PNSS-1. The single cell has a maximum power point voltage $\left(V_{\mathrm{mp}}\right)$ of $2396 \mathrm{mV}$ and short circuit current density $\left(J_{\mathrm{SC}}\right)$ of $17.67 \mathrm{~mA} / \mathrm{cm}^{2}$ which gives 0.42 A current. According to the PNSS-1 solar panel design requirement, a single solar panel should generate at least $50 \mathrm{~W}$ with maximum output voltage of $80 \mathrm{~V}$ and minimum voltage should not be less than $40 \mathrm{~V}$ under normal sunlight conditions at sun incidence angle of $5^{\circ}$. It means that multiple
TABle 1: GaAs triple-junction solar cell characteristics.

\begin{tabular}{lc}
\hline Type & $G a \ln P_{2} / \mathrm{GaAs} / \mathrm{Ge}$ \\
\hline Cell dimension & $39.8 \mathrm{~mm} \times 60.4 \mathrm{~mm}$ \\
Short circuit current density $\left(J_{\mathrm{sc}, \mathrm{mA} / \mathrm{cm}^{2}}\right)$ & 17.67 \\
Open circuit voltage $\left(V_{\mathrm{oc}, \mathrm{mV}}\right)$ & 2700 \\
$\begin{array}{l}\text { Maximum power point current density } \\
\left(J_{\mathrm{mp}, \mathrm{mA} / \mathrm{cm}^{2}}\right)\end{array}$ & 17.13 \\
Maximum power point voltage $\left(v_{\mathrm{mp}, \mathrm{mV}}\right)$ & 2396 \\
$\begin{array}{l}\text { Fill factor }(\mathrm{FF}) \\
\text { Efficiency }(\eta)\end{array}$ & 0.86 \\
$\begin{array}{l}\text { Change in open circuit voltage per degree } \\
\text { change in temperature }\left(\Delta V_{\mathrm{oc}} / \Delta T\right)\end{array}$ & $-5.589 \mathrm{mV} /{ }^{\circ} \mathrm{C}$ \\
$\begin{array}{l}\text { Change in maximum power point voltage per } \\
\text { degree change in temperature }\left(\Delta V_{\mathrm{mp}} / \Delta T\right)\end{array}$ & $-5.964 \mathrm{mV} /{ }^{\circ} \mathrm{C}$ \\
\hline
\end{tabular}

string arrays will be used for the solar panel design. The efficiency of the solar cell array is always less than the sum of individual cells because of the manufacturing issues and environmental factors, collectively called as the degradation factor [20]. For the solar panel design calculations, it is essential to take into account the degradation factor. The data of the required triple-junction GaAs solar cell for this design is given in Table 1.

For calculation of the minimum voltage limit of a single solar cell, the maximum temperature limit is applied, because as the temperature increases above the standard test conditions (STC), i.e., $25^{\circ} \mathrm{C}$, the voltage reduces per degree rise in temperature. Let us assume that the maximum temperature is $85^{\circ} \mathrm{C}$. Difference between maximum temperature and STC is $60^{\circ} \mathrm{C}$ which will reduce the single cell minimum voltage to $V_{\min }=2.396+60 \times\left(-5.94 \times 10^{-3}\right)=2.038 \mathrm{~V}$ where $-5.94 \times 10^{-3}$ is the change in open circuit voltage per degree change in temperature $\left(\Delta V_{\text {oc }} / \Delta T\right)$ as given in Table 1. After applying the degradation factor of 0.85 , the resultant minimum voltage for the single cell becomes $1.732 \mathrm{~V}$.

For upper voltage limit calculation, minimum operating temperature is considered. Let us assume that the minimum temperature is $-45^{\circ} \mathrm{C}$. Difference between minimum temperature and STC is $-70^{\circ} \mathrm{C}$ which will increase the single cell maximum voltage to $V_{\max }=2.396+(-70 \times(-5.589 \times$ $\left.\left.10^{-3}\right)\right)=3.09 \mathrm{~V}$ where $-5.589 \times 10^{-3}$ is the change in MPP voltage per degree change in temperature $\left(\Delta V_{\mathrm{mp}} / \Delta T\right)$ as given in Table 1. After applying the degradation factor of 0.85 , the resultant maximum voltage becomes $2.63 \mathrm{~V}$.

From the degradation analysis given above, we can find the minimum and maximum number of cells required to achieve the upper and lower voltage limits. The maximum number of the solar cell limit is found by dividing the upper voltage limit with the single cell maximum voltage, i.e., $(80 \mathrm{~V} / 2.63 \mathrm{~V})=31$, while the minimum number of the required cell limit is found by dividing the lower voltage limit with the single cell minimum voltage, i.e., $(40 \mathrm{~V} / 1.73 \mathrm{~V})=23$.

After applying the degradation factor, the single cell output current is $0.36 \mathrm{~A}$. 


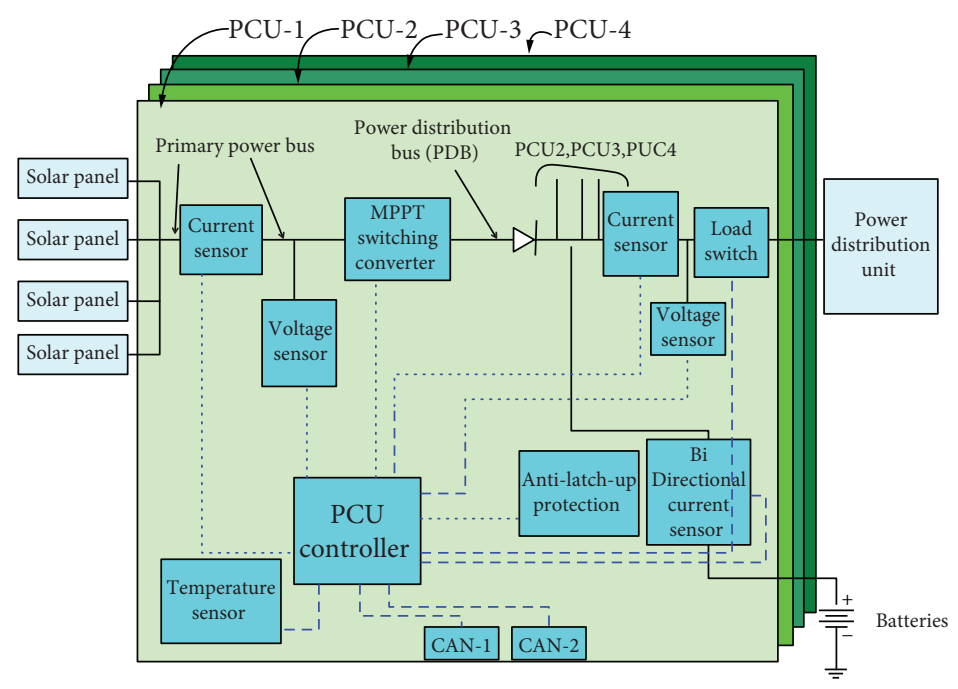

(a)
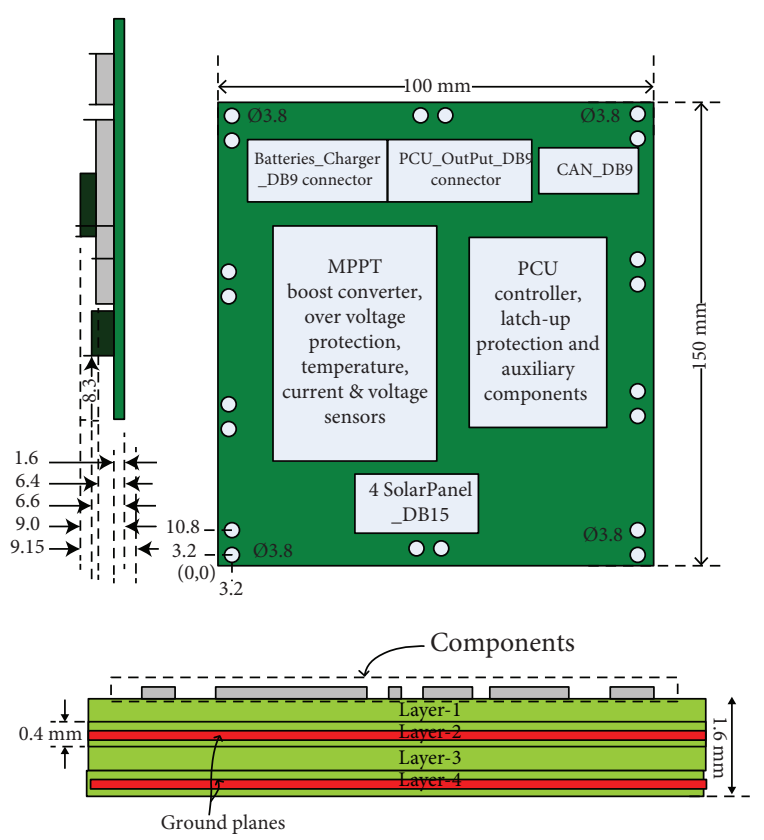

(b)

FIgUre 2: (a) PCM block diagram and (b) PCB dimensions.

According to the design requirements, the average output power from the solar panel should not be less than $50 \mathrm{~W}$. The power analysis shows that minimum required power is $40 \mathrm{~W}$ and maximum required power is $60 \mathrm{~W}$. Single cell average output power is $0.78 \mathrm{~W}$. The solar panel has dimensions of $470 \mathrm{~mm} \times 450 \mathrm{~mm}$, and single cell dimensions are $39.8 \mathrm{~mm} \times 60.4 \mathrm{~mm}$. It means that a maximum of 87 solar cells can be accommodated on the solar panel. Excluding the area required for the sun sensor, temperature sensor, and bypass diodes, the total number of cells that can be accommodated on the solar panel is 64. These cells are divided into two strings; each has 32 solar cells connected in series. The average voltage of the single cell is $2.18 \mathrm{~V}$ and maximum numbers of solar cells are 32 which result in average output voltage and current of $69 \mathrm{~V}$ and $0.72 \mathrm{~A}$, respectively. The resultant output power after applying all the degradation factors is $50 \mathrm{~W}$. A bypass diode is connected in parallel to each solar cell which ensures proper operation of the single cell if one of them is damaged. A protection diode is added at the end of each string of 32 solar cells to protect it from reverse current flow.

For the SPM to operate within its temperature limits, a glass-protected NTC (negative temperature coefficient) thermistor is mounted onto the solar panel for protection against transient voltage spikes. Output voltage of the sensor is linearly proportional to temperature. Its resistance range varies between $2.2 \mathrm{k}$ and $100 \mathrm{k}$, which is highly accurate with $1 \%$ of tolerance.

\section{Power Conditioning Module (PCM)}

The PCM is responsible for converting solar panels' unstable voltage $(40 \mathrm{~V} \sim 80 \mathrm{~V})$ into a stable voltage level delivered to the PDB $(28 \pm 6 \mathrm{~V})$. It is also responsible for voltage regulation, battery charging, and health monitoring of different PCM subsystems. A MPPT-based buck converter is designed and simulated to operate the solar panel at its MPP. To achieve maximum power point, the MPPT buck converter can be designed using different MPPT algorithms. Most common algorithms for recognition of MPP are the constant voltage method [21], short-current pulse method [22], open voltage method [23], perturb and observe method [24], and incremental conductance method [25]. These seven MPPT algorithms are examined and evaluated on the basis of efficiency [26]. The perturb and observe method shows the best result and better efficiency as compared to others [27, 28]; therefore, this algorithm is chosen for the PCM MPPT design. Batteries are charged and discharged from the PDB through a battery charging system. The PCM controller is used to perform the power management and control operations of the entire unit. It communicates with the $\mathrm{OBC}$ of the satellite using redundant CAN buses. PCM casing dimensions and input/output power/signal have standardized connectors which result in a fully modular system that can be attached and detached as a separate unit to the rest of the satellite subsystems. Figure 2(a) shows the conceptual-level block diagram of the PCM subsystem while Figure 2(b) shows the PCB dimensions of the PCM. Casing dimensions of the PCM are shown in Figure 3.

3.1. PCM Design Description. The PCM consists of four modular and redundant MPPT units and CAN controller. Each MPPT unit has a local microcontroller (MSP430) to which different subsystems like MPPT switching converter, current, voltage, and temperature sensors are connected. These controllers are CMOS-based COTS components which are prone to radiation. In order to protect them from radiation damage, a latch-up protection system is designed for the 


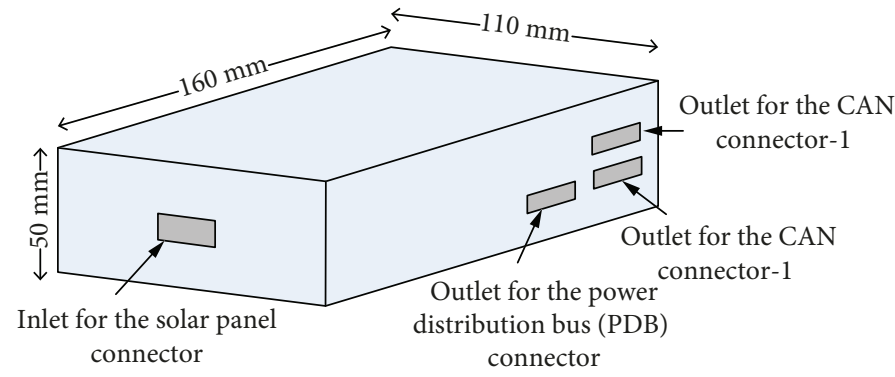

Figure 3: Casing dimensions of the PCM.

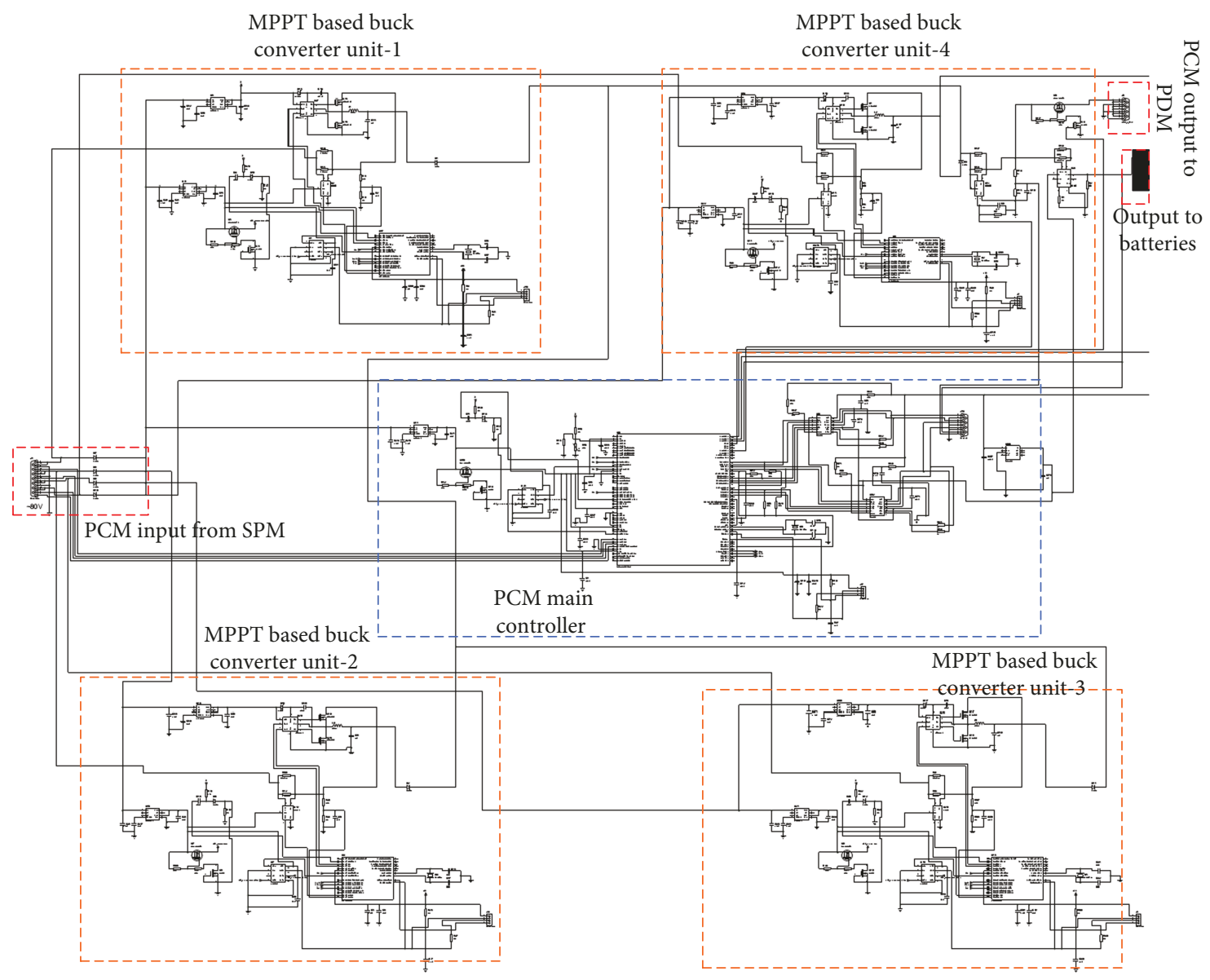

FIgURE 4: PCM complete schematic.

PCM unit. The four MPPT controllers (MSP430) and CAN controller (PIC24HJ256GP10) are communicating with each other through SPI protocol while the CAN microcontroller is communicating with the $\mathrm{OBC}$ of the satellite through an embedded CAN transceiver system having redundant CAN buses. A schematic of the PCM is shown in Figure 4.

In the PCM design, the perturb and observe algorithm is opted to continuously locate the maximum power point and extract maximum power from the solar panels connected with it. The $\mathrm{P} \& \mathrm{O}$ algorithm works by continuously calculating the power (current and voltage) from PV arrays and comparing it with preceding calculated power values. If there is a difference and the power calculated from the current cycle is greater than the previous cycle, the controller moves the
MPP in that direction by increasing the duty cycle; otherwise, if the power levels are same, it is the maximum power point [27]. Current, voltage, and temperature sensors ensure proper voltage, current, and temperature limits of the solar panel output and on the PDB level. One set of voltage and current sensors is connected at the output of the solar panel (input of the buck converter) in all four redundant MPPT units, and a second set of current and voltage sensors is connected at the output of the buck converter. A bidirectional current sensor is employed at the input of batteries to monitor the battery charging and discharging currents. Latch-up protection and watchdog timer blocks protect the MPPT local controller of each unit from single-event latch-ups. A single MPPT buck converter unit is shown in Figure 5. 


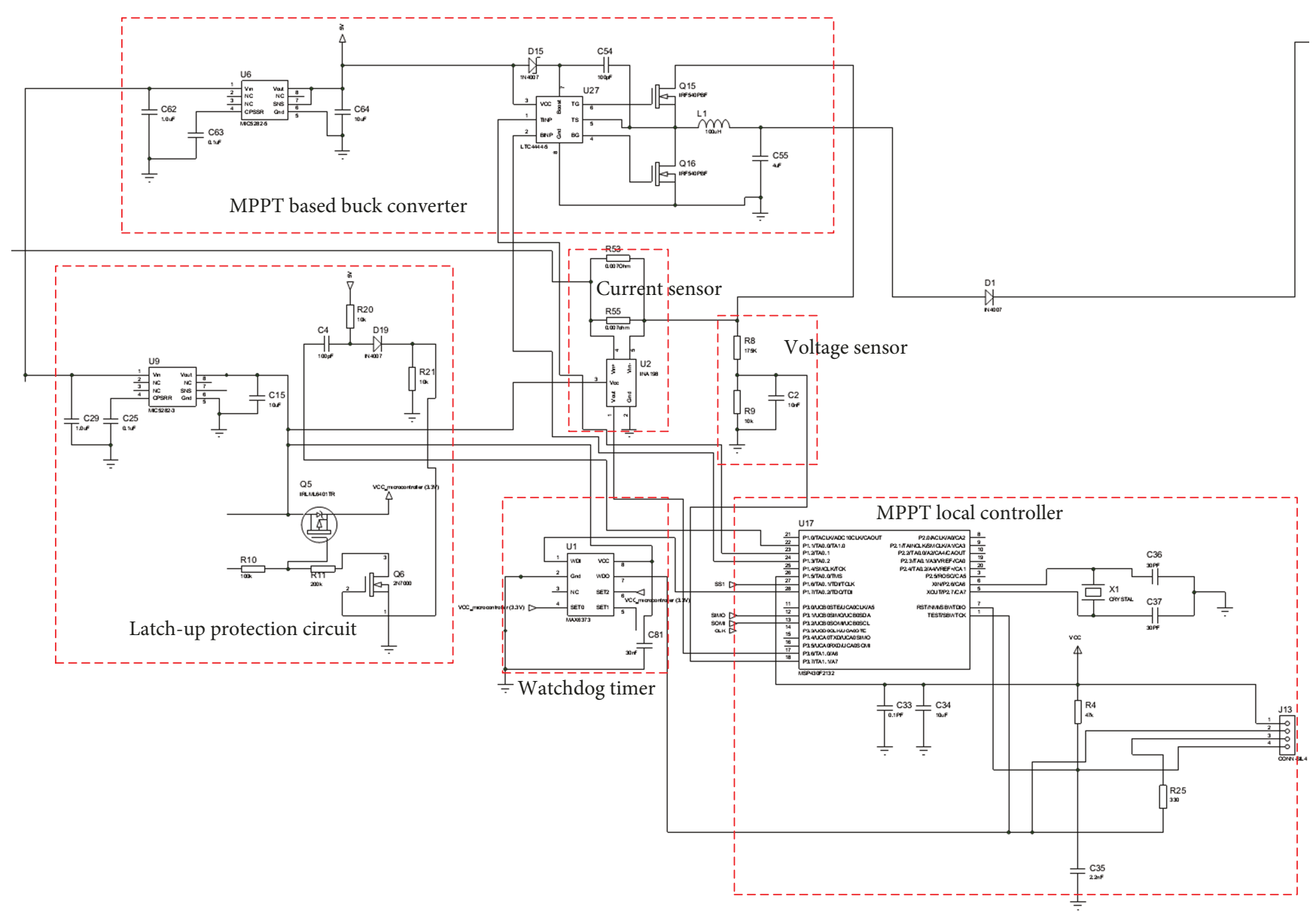

FIgURE 5: Single MPPT buck converter unit.

3.2. Latch-Up Protection System. MPPT local controller units of PCM are CMOS-based COTS devices which are sensitive to radiation [29]. A latch is a momentary effect in which the device gets short circuited and high current flows through the device from the power supply to ground which damages the device. The latch-up problem can be solved by using bipolar devices, which are immune to latch-up because they require an extremely high energy to trigger this event. But the microcontrollers are CMOS-based and require latch-up protection circuits. To avoid this condition, the microcontroller supply should be disconnected on a temporary basis. A latch-up protection circuit was designed and simulated to cut off the microcontroller supply during latch-up to protect the device from damage. The simulations of the latch-up protection circuit designed for the PCM are shown in Figure 6 , where V1 is the microcontroller supply voltage connected with the microcontroller VCC pin, through MOSFET $\mathrm{M} 2$ and M1 switching. V3 is the voltage coming from the microcontroller pin. In normal operation condition, $\mathrm{C} 1$ is charged through R4 from the supply V2 and MOSFET M1 is $\mathrm{ON}$, which further keeps $\mathrm{M} 2 \mathrm{ON}$, and the voltage supply $\mathrm{V} 1=5 \mathrm{~V}$ is connected with the microcontroller VCC pin. Figure 6(b) shows the waveforms of the latch-up protection circuit of Figure 6(a). The waveform V (R3:2) shows the microcontroller supply voltage, $\mathrm{V}(\mathrm{M} 1: \mathrm{g})$ represents the voltage across the $\mathrm{C} 1$ capacitor, and $\mathrm{V}(\mathrm{C} 1: 1)$ indicates the microcontroller pin voltage. In waveforms, the normal operation state is shown from time 0 to $4 \mathrm{~ms}$ and $8 \mathrm{~ms}$ to $12 \mathrm{~ms}$. During latch-up, the microcontroller pin, which is represented in the simulation circuit by V3, will be grounded and capacitor $\mathrm{C} 1$ will discharge. As a result of the $\mathrm{C} 1$ discharge, M1 and M2 will switch off and supply to the microcontroller VCC pin will cut off. The off state is shown in the simulation waveform from time $4 \mathrm{~ms}$ to $8 \mathrm{~ms}$ and $12 \mathrm{~ms}$ to $16 \mathrm{~ms}$. The off state time duration is decided by the RC time constant of $\mathrm{C} 1$ and $\mathrm{R} 4$ components of the simulation circuit. At the moment, we have chosen it to be $4 \mathrm{~ms}$ as seen from the simulation waveform of Figure $6(\mathrm{~b})$. The implemented latch-up protection circuit is shown in Figure 5.

3.3. Data Interface. The PCM has a dual redundant CAN interface with $\mathrm{OBC}$ for all telemetries and all of its telecommands using DB9 connectors. It provides sufficient telemetries (on CAN interface) in order to monitor the health of its own along with the health of all solar panels and battery. Telemetries of the PCM include the following at minimum:

(1) Primary bus voltage

(2) Primary bus current 


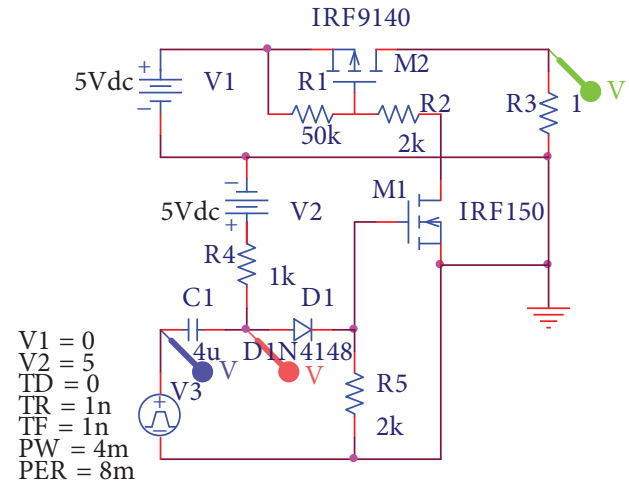

(a)

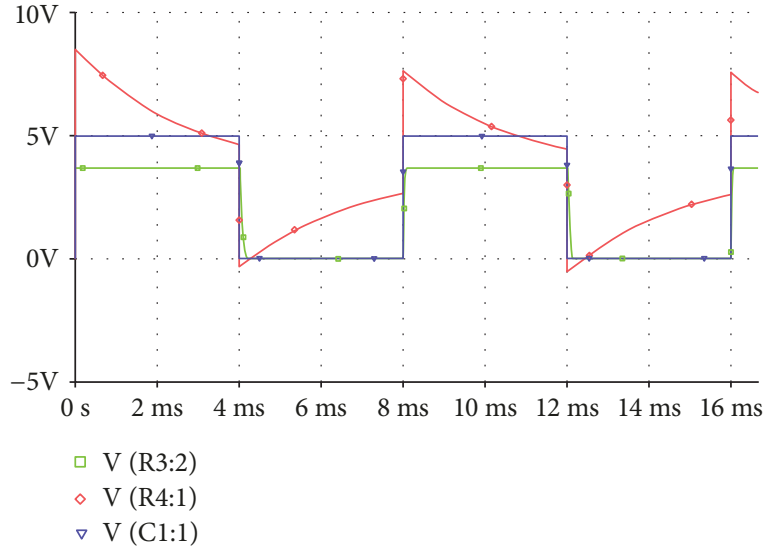

(b)

FIGURE 6: Latch-up protection simulation (a) circuit and (b) waveforms.

(3) Battery charge and discharge current

(4) Battery temperature

(5) Output current of each solar panel

(6) Voltage of each solar panel

(7) Temperature of each solar panel

The PCM collects analog temperature telemetries from each solar panel and battery, and it provides these telemetries (along with all other telemetries) to the $\mathrm{OBC}$ on the CAN interface.

3.4. Power Interface. PCM receives 2:1 redundant input power lines separately from four independent solar panels through the DB9 connector and provides $2: 1$ redundant output lines for battery charging as well as to PDM at bus voltage level using DB9 connectors. A gap of at least one unused pin is kept between positive power lines and their returns in all power interface connectors (for both input and output). To ensure modularity, all output connectors are female type and input connectors are male type.

3.5. Simulations of MPPT Buck Converter. The output range of the solar panel is $40 \mathrm{~V} \sim 80 \mathrm{~V}$ as mentioned earlier. To cover this wide range input voltage to a stable output voltage, an MPPT buck converter is designed with wide range input. First, design considerations are made to select the appropriate values of filter components, i.e., inductor, capacitor, and resistor for an efficient and robust MPPT buck converter. The values selected according to the design consideration are assigned to all devices shown in Figure 7. The standard equations (1) and (2) are used for inductor $(L)$ and capacitor (C) value selection [30], respectively.

$$
\begin{aligned}
& L=\frac{\left(V_{\mathrm{s}}-V_{\mathrm{o}}\right) \times D}{\left(\Delta I_{\mathrm{L}} \times f\right)}, \\
& C=\frac{1-D}{8 L \times\left(\Delta V_{o} / V_{o}\right) \times f^{2}} .
\end{aligned}
$$

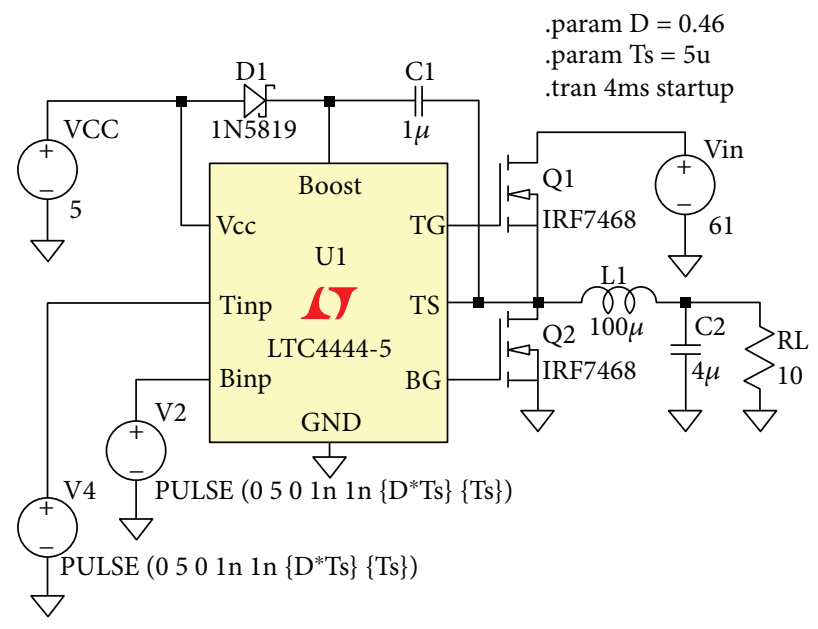

FIgURE 7: Simulation schematic of MPPT buck converter.

The LTspice simulation schematic of the buck converter with its driver circuitry is shown in Figure 7. The four MPPT buck converters are mounted on two PCBs, i.e., each PCB has two buck converter units. In order to avoid synchronization problem, $10 \mathrm{kHz}$ frequency gap is kept between all four converters. The designed frequency for the 1st MPPT converter unit is $180 \mathrm{kHz}$, while the $2 \mathrm{nd}$, 3rd, and 4 th converters have $190 \mathrm{kHz}, 200 \mathrm{kHz}$, and $210 \mathrm{kHz}$ switching frequencies, respectively. All the components are selected on the basis of power loss analysis and small dimensions.

The two pulses V2 and V4 in Figure 7 represent the PWM signals coming from the microcontroller to increase or decrease the duty cycle according to the perturb and observe algorithm. The converter is simulated for a wide input voltage range, i.e., $80 \mathrm{~V}, 70 \mathrm{~V}, 61 \mathrm{~V}, 50 \mathrm{~V}$, and $41 \mathrm{~V}$, and the respective output voltage is measured which is the PDB voltage level $(28 \pm 6 \mathrm{~V})$. The output current, input and output powers, and resultant efficiency are measured for the four designed buck converter units. The simulations of the MPPT buck converter are given in Figures 8-17, and simulation results are summarized in Table 2. 


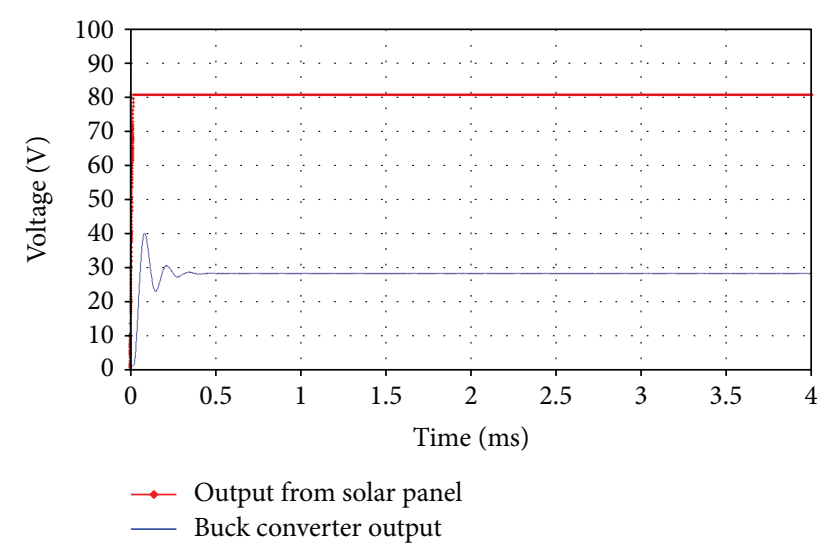

FIGURE 8: Input and output voltage waveforms of the MPPT buck converter for $80 \mathrm{~V}$ input.

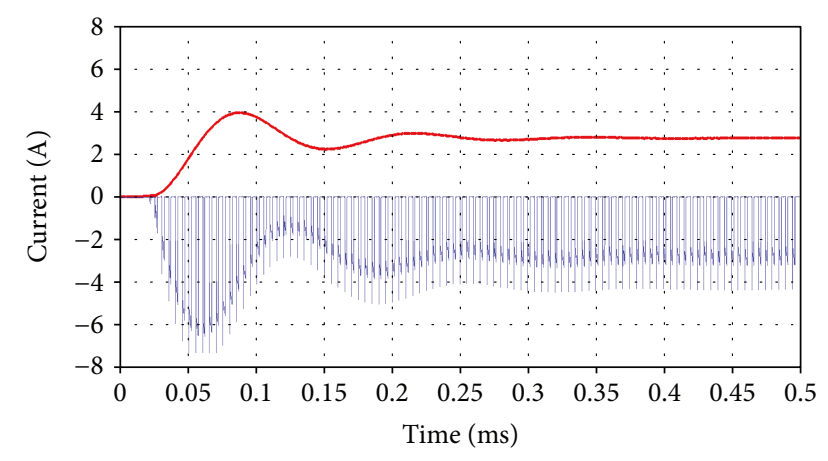

- - Output current of buck converter

_ Buck converter switching current

FIGURE 9: Input and output current waveforms for $80 \mathrm{~V}$ input.

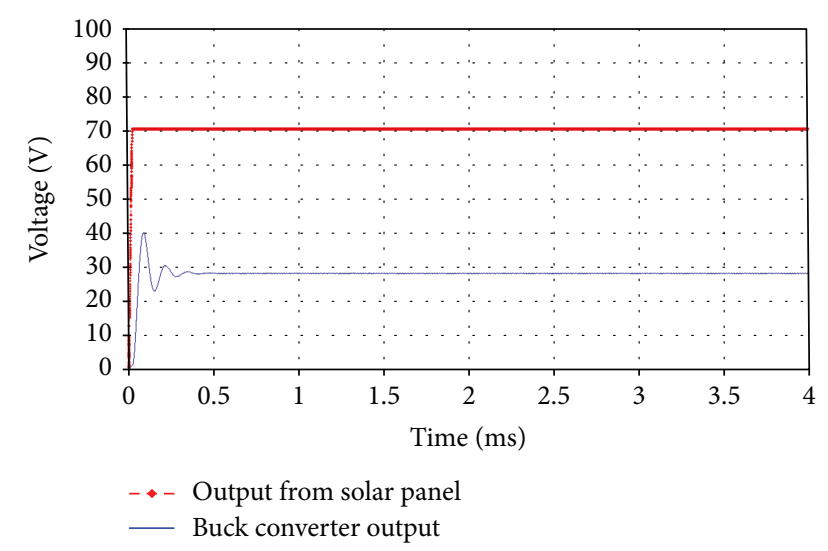

FIGURE 10: Input and output voltage waveforms for $70 \mathrm{~V}$ input.

Simulation results shown in Table 2 clearly demonstrate that the designed MPPT buck converter has a wide input range and possesses high efficiency (95.30\% to 96.75\%).

\section{Power Distribution Module (PDM)}

PDM is the submodule of the Electric Power System (EPS), responsible for the conversion of the $\mathrm{PDB}$ voltage level into

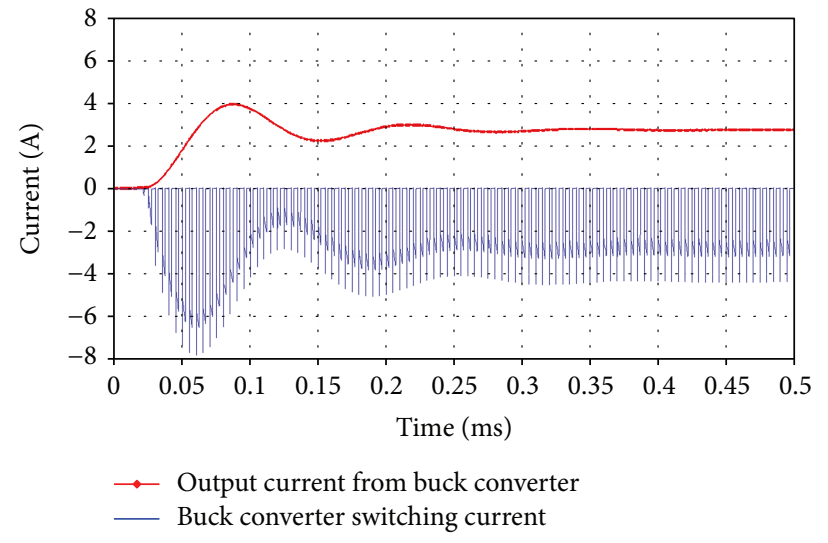

FIGURE 11: Input and output current waveforms for $70 \mathrm{~V}$ input.

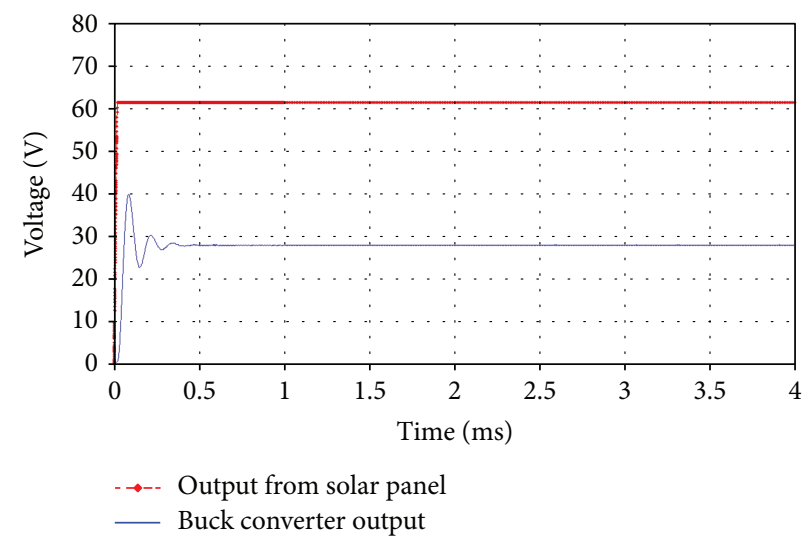

FIGURE 12: Waveforms of input and output voltage for $61 \mathrm{~V}$ input.

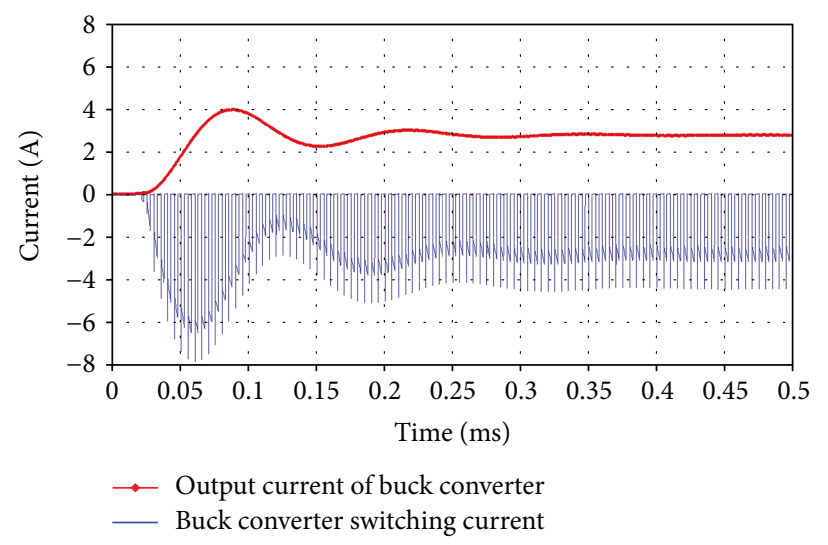

FIGURE 13: Input and output current waveforms for $61 \mathrm{~V}$ input.

the lower voltage levels and for distributing it to loads. EMI filtration is done by the PDM. There are certain protection systems installed on each distribution line. The main purpose of these protection systems is to limit the electromagnetic noise produced on the main bus and also to overcome the fault propagation. Inside the PDM, there is implementation of ON/OFF switching of all the switchable loads. With the help of telecommands, these switches are controlled from the OBC. To overcome failure and to improve the reliability, 


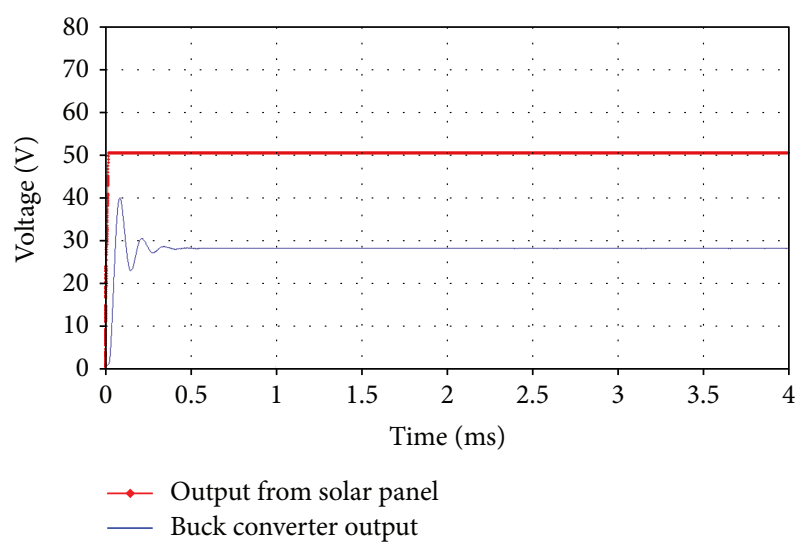

FIGURE 14: Input and output voltage waveforms for $50 \mathrm{~V}$ input.

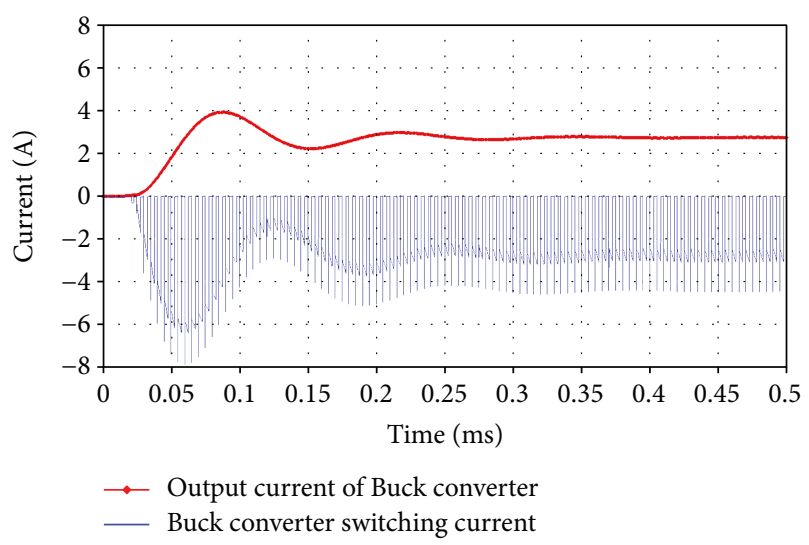

FIGURE 15: Input and output current waveforms for $50 \mathrm{~V}$ input.

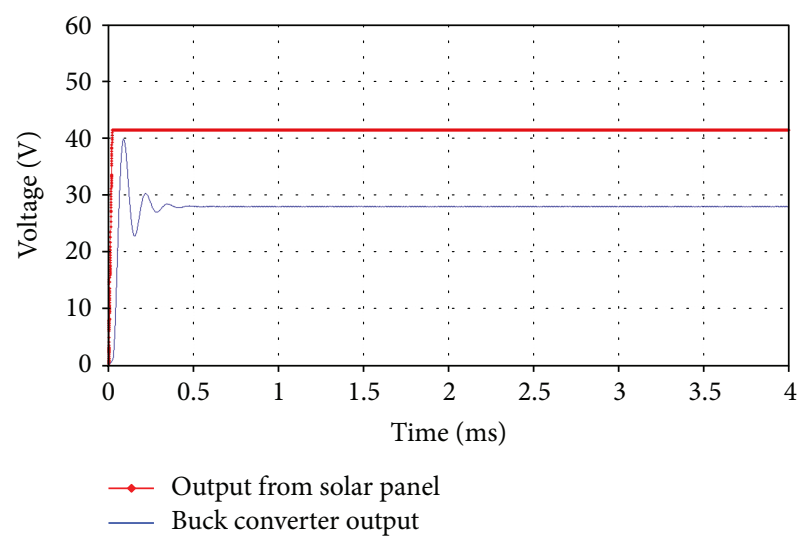

FIGURE 16: Input and output voltage waveforms for $41 \mathrm{~V}$ input.

redundancy is provided at all levels. No single electrical component failure in the PDU disables or degrades its required functions in a way that may lead to mission failure.

The power distribution unit receives primary power from the PCM at bus voltage $28 \mathrm{~V} \pm 6 \mathrm{~V}$ (unregulated) and generates regulated secondary voltage levels at $12 \mathrm{~V}$ and $5 \mathrm{~V}$. Current, voltage, and temperature sensors are mounted in the PDM unit to monitor and ensure proper operation of the module. The function of these sensors is to check current,

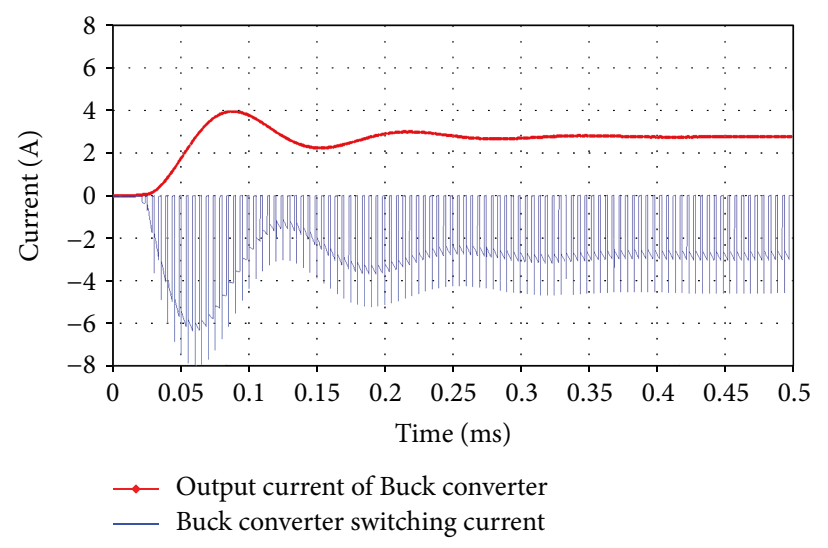

FIGURE 17: Input and output current waveforms for $41 \mathrm{~V}$ input.

voltage, and temperature limitations. The PDM controller further communicates with the $\mathrm{OBC}$ of the microsatellite through redundant CAN buses. The block diagram of the PDM is shown in Figure 18, and the design schematic is shown in Figure 19.

4.1. Power Regulators. The power regulators convert the PDB voltage level to low voltage levels (i.e., $5 \mathrm{~V}$ and $12 \mathrm{~V}$ ) used by different subsystem components. For this purpose, the PDM unit requires two switching regulators. To meet the power and redundancy requirement for $12 \mathrm{~V}$ regulated output, the PDM has two redundant $12 \mathrm{~V}$ regulators with part number MGDD-20-R-E. For $5 \mathrm{~V}$, four regulators with part number MGDB-35-H-C are connected in parallel to meet the power and redundancy requirements.

4.2. Power Interface. The PDM receives unregulated power through the PDB from the PCM and regulates it according to the requirement. For redundancy, the PDM receives $2: 1$ power lines from the PCM at $28 \mathrm{~V} \pm 6 \mathrm{~V}$. The PDM has a total of 40 output lines of different voltage and current levels. Some of these lines are pair switchable and some are nonswitchable as shown in Table 3.

All output distribution lines of the PDM are protected against short circuit current and transient voltage spikes. A protection concept is implemented in the PDM to avoid fault and failure propagation between the loads. All PDM subsystems are connected and intercommunicate with the PDM controller (PIC24HJ256GP10) for monitoring and controlling purposes.

4.3. Data Interface. The PDM has a dual redundant CAN interface with the OBC for all telemetries and all of its telecommands. With the help of the CAN interface, the OBC receives certain telemetries from the PDM in order to check all the switchable distribution lines as well as to monitor the health of the primary and secondary voltages. In order to control the ON/OFF operation of switchable lines, the PDM has the capability of receiving telecommands through the CAN interface. Standard D-type connectors are used for CAN buses. 
TABLE 2: Simulation results of MPPT buck converter designed for PCM.

\begin{tabular}{ccccccccc}
\hline S. no & $\begin{array}{c}\text { Input voltage } \\
\left(V_{\text {in }}\right)\end{array}$ & $\begin{array}{c}\text { Output voltage } \\
\left(V_{\mathrm{o}}\right)\end{array}$ & $\begin{array}{c}\text { Duty cycle } \\
(D)\end{array}$ & $\begin{array}{c}\text { Input current } \\
\left(I_{\mathrm{in}}\right)\end{array}$ & $\begin{array}{c}\text { Output current } \\
\left(I_{\mathrm{o}}\right)\end{array}$ & $\begin{array}{c}\text { Input power } \\
\left(P_{\text {in }}\right)\end{array}$ & $\begin{array}{c}\text { Output power } \\
\left(P_{\mathrm{o}}\right)\end{array}$ & $\begin{array}{c}\text { Efficiency } \\
(\eta)\end{array}$ \\
\hline 1 & $80 \mathrm{~V}$ & $27.33 \mathrm{~V}$ & 0.35 & $0.981 \mathrm{~A}$ & $2.73 \mathrm{~A}$ & $78.28 \mathrm{~W}$ & $74.61 \mathrm{~W}$ & 95.30 \\
2 & $70 \mathrm{~V}$ & $27.36 \mathrm{~V}$ & 0.40 & $1.11 \mathrm{~A}$ & $2.73 \mathrm{~A}$ & $77.50 \mathrm{~W}$ & $74.69 \mathrm{~W}$ & 96.37 \\
3 & $61 \mathrm{~V}$ & $27.45 \mathrm{~V}$ & 0.46 & $1.28 \mathrm{~A}$ & $2.74 \mathrm{~A}$ & $77.87 \mathrm{~W}$ & $75.21 \mathrm{~W}$ & 96.58 \\
4 & $50 \mathrm{~V}$ & $27.45 \mathrm{~V}$ & 0.56 & $1.56 \mathrm{~A}$ & $2.74 \mathrm{~A}$ & $77.79 \mathrm{~W}$ & $75.21 \mathrm{~W}$ & 96.68 \\
5 & $41 \mathrm{~V}$ & $27.39 \mathrm{~V}$ & 0.68 & $1.89 \mathrm{~A}$ & $2.73 \mathrm{~A}$ & $77.28 \mathrm{~W}$ & $74.77 \mathrm{~W}$ & 96.75 \\
\hline
\end{tabular}

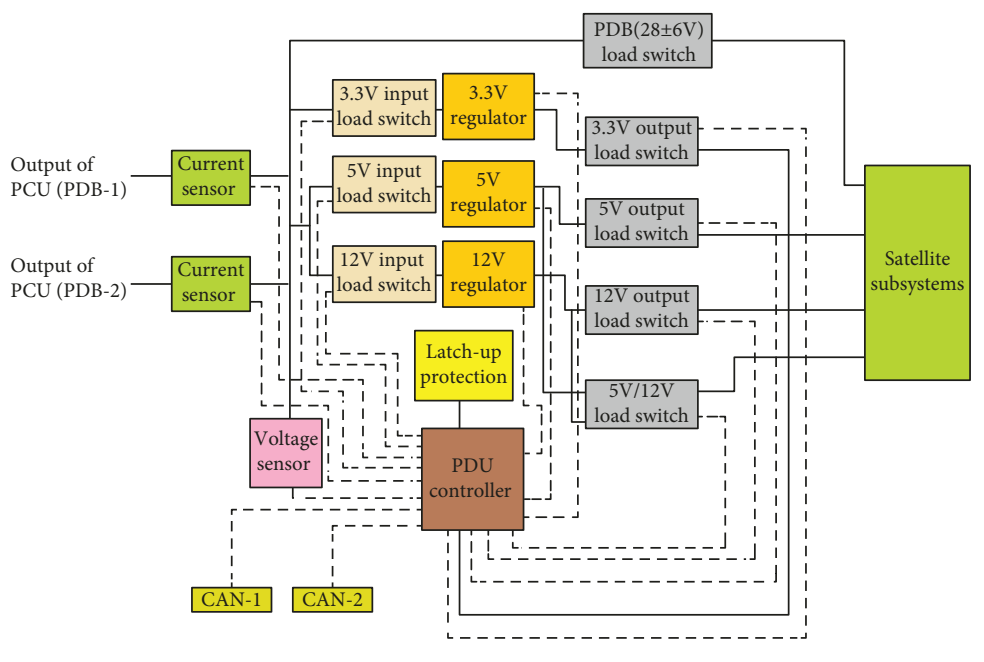

(a)

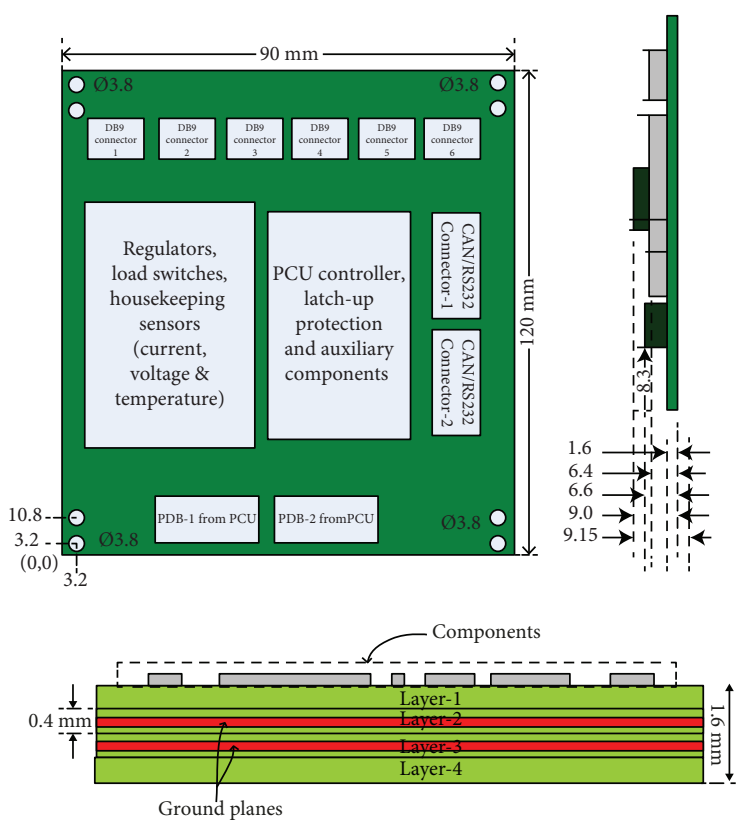

(b)

FIgURE 18: (a) PDM block diagram and (b) PCB dimensions.

\section{Attitude Control System (ACS)}

Due to dimension and weight constraints of small satellites, designers are focusing on the miniaturization of subsystems such as power, attitude determination and control, telecommunication, and payload. In the PNSS-1 attitude control subsystem design, the major aim was to achieve a system with small dimensions and weight. The available options for the attitude control were permanent magnets, reaction wheels, and magnetic rods [31, 32]. Permanent magnets are cheaper, simpler, and lightweight, but they have inadequate pointing accuracy. The other options were magnetic rods and reaction wheels which have better pointing accuracy, but the problem is their price, weight, and size which make them unsuitable for small satellites. To achieve the goal of a miniaturized compatible system with PNSS-1, an innovative concept of an embedded magnetorquer is introduced. The magnetorquer coil is copper traces embedded inside the internal layers of the solar panel PCB. Solar panel PCB is an eight-layer PCB with copper traces in five internal layers. These copper traces are just like the magnetorquer rod producing a magnetic field when current flows through it.
5.1. PNSS-1 Embedded Magnetorquer Coil. The magnetorquer coil works on the motor action concept that when a current carrying the coil is placed in a magnetic field, a torque is exerted on the coil. The current-carrying coil generates a magnetic moment which interacts with the already existing magnetic field and produces torque. According to Fleming's left-hand rule, the middle finger gives the direction of the magnetic moment, the index finger shows the direction of the existing magnetic field, and the thumb indicates the direction of exerted torque. Let us suppose the currentcarrying coil shown in Figure 20 with the magnetic moment (D) generated is toward the page and is given by

$$
\vec{D}=N \cdot S \cdot I
$$

where $N$ is the number of turns of the coil, $S$ is the area of the coil, and $I$ is the current flowing through the coil.

If the magnetic field $(\vec{B})$ direction is toward the right side of the paper, then the torque generated is toward the bottom of the paper and can be found by

$$
\vec{\tau}=\vec{D} \times \vec{B}=D B \sin \theta \vec{n}
$$




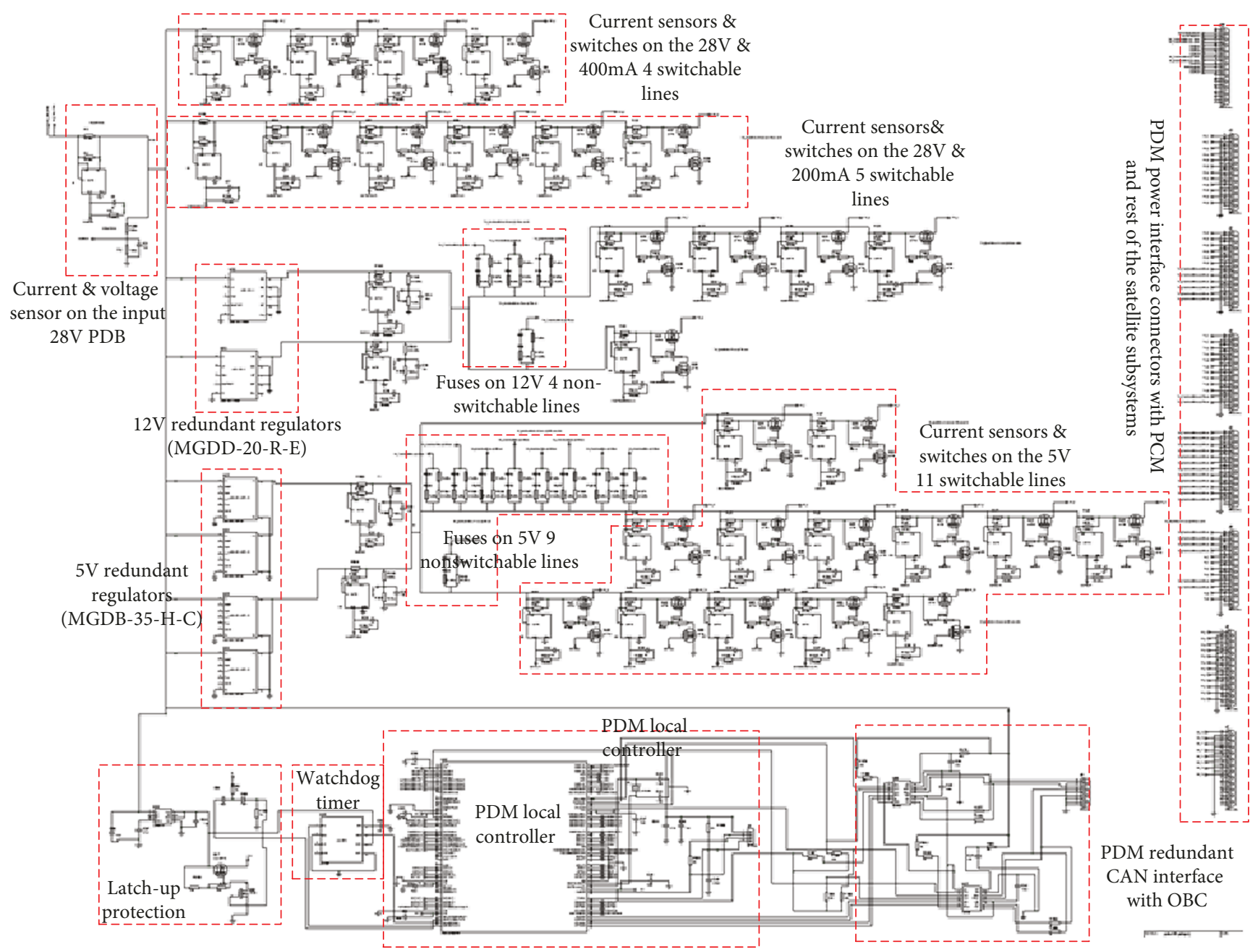

FIGURE 19: Design schematic of PDM.

TABLE 3: Voltage distribution of switchable/nonswitchable lines.

\begin{tabular}{lccc}
\hline S. no & Voltage level & $\begin{array}{c}\text { No. of power lines } \\
\text { and current rating }\end{array}$ & $\begin{array}{c}\text { Switchable/ } \\
\text { nonswitchable }\end{array}$ \\
\hline 1 & $28 \mathrm{~V}$ & 4 lines at $400 \mathrm{~mA}$ each & Switchable \\
2 & $28 \mathrm{~V}$ & 5 lines at $200 \mathrm{~mA}$ each & Switchable \\
3 & $12 \mathrm{~V}$ & 3 lines at $400 \mathrm{~mA}$ each & Nonswitchable \\
4 & $12 \mathrm{~V}$ & 4 lines at $400 \mathrm{~mA}$ each & Switchable \\
5 & $12 \mathrm{~V}$ & 1 line at $100 \mathrm{~mA}$ each & Switchable \\
6 & $12 \mathrm{~V}$ & 1 line at $100 \mathrm{~mA}$ each & Nonswitchable \\
7 & $5 \mathrm{~V}$ & 2 lines at $2000 \mathrm{~mA}$ each & Switchable \\
8 & $5 \mathrm{~V}$ & 8 lines at $800 \mathrm{~mA}$ each & Nonswitchable \\
9 & $5 \mathrm{~V}$ & 6 lines at $800 \mathrm{~mA}$ each & Switchable \\
10 & $5 \mathrm{~V}$ & 1 line at $200 \mathrm{~mA}$ each & Nonswitchable \\
11 & $5 \mathrm{~V}$ & 5 lines at $200 \mathrm{~mA}$ each & Switchable \\
\hline
\end{tabular}

where $\vec{n}$ is the direction of torque $\vec{\tau}$ and $\theta$ is the angle between $\vec{D}$ and $\vec{B}$.

Earth is a big magnet, and in low earth orbit (LEO), from $400 \mathrm{~km}$ to $2000 \mathrm{~km}$ altitude, the earth magnetic field varies between 0.15 gauss and 0.45 gauss [33]. Four solar panel

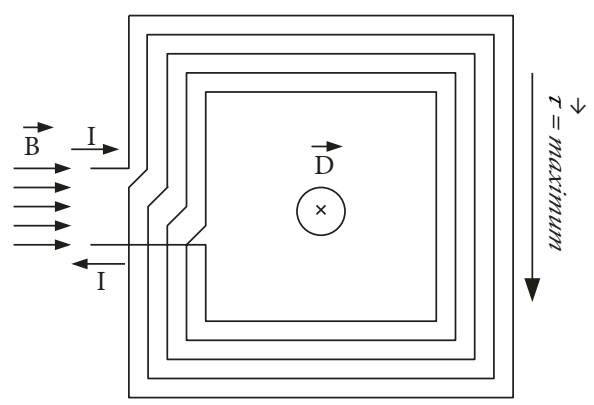

FIgURE 20: Current-carrying coil in presence of magnetic field.

modules with embedded magnetorquer coils are mounted on the four external faces of the PNSS-1 satellite as shown in Figure 21. When current flows through the coils, a magnetic moment is generated which interacts with the earth magnetic field and a torque is exerted on the satellite to rotate it in the desired direction.

The coils are embedded in the five internal layers of the solar panel PCB, i.e., the $2^{\text {nd }}, 3^{\text {rd }}, 4^{\text {th }}, 5^{\text {th }}$, and $6^{\text {th }}$ layers. These five coils are treated as individual coils and attached through switches. By changing the arrangement 


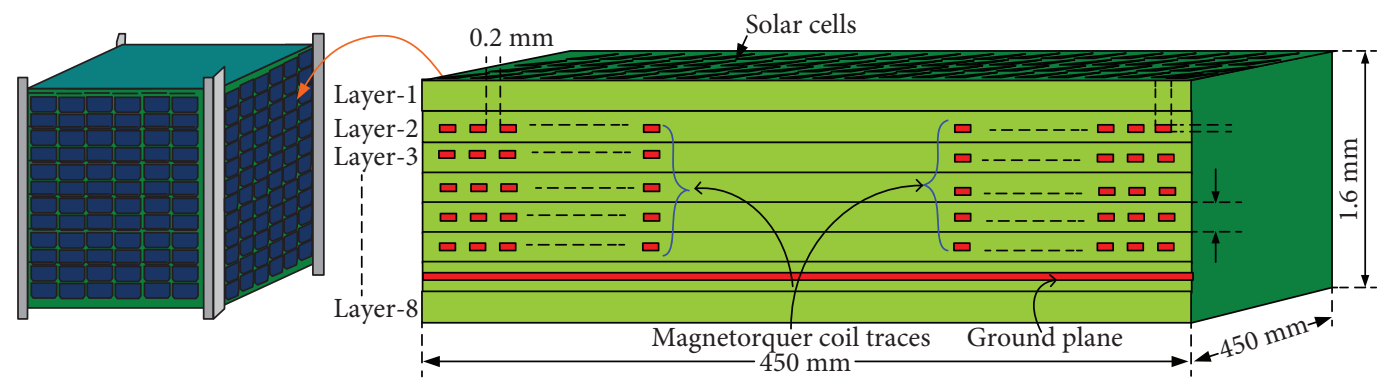

FIGURE 21: Solar panel module (PNSS-1) cross-sectional view with embedded magnetorquer.

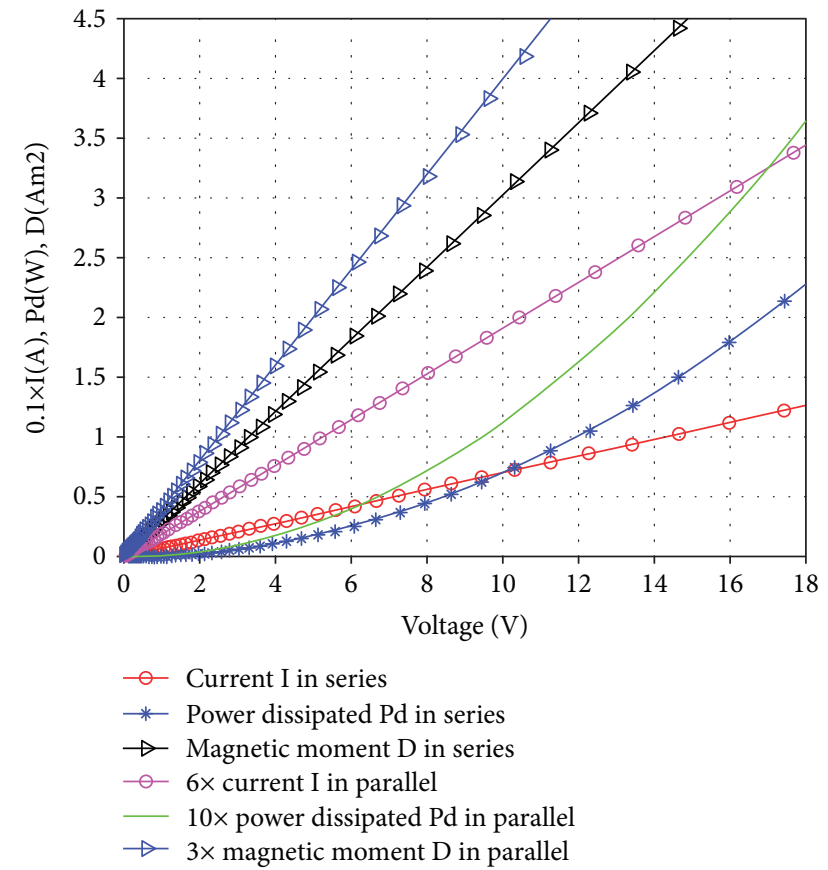

FIGURE 22: Voltage versus current, magnetic moment, and power dissipated for four-coil combination (series/parallel).

of these switches, the five coils can be attached/detached in different configurations such as a single coil, five in series, and five coils in parallel. According to the satellite torque requirements, the magnetorquer coil should be able to generate a specific magnetic field. To generate the required magnetic moment of PNSS-1, the magnetorquer coil composed of copper traces with 60 turns in each layer and a total of 300 turns is embedded in five internal layers. Each coil trace has $1.8 \mathrm{~mm}$ width and $18 \mu \mathrm{m}$ thickness. Space between two adjacent traces is $0.2 \mathrm{~mm}$.

Current, magnetic moment, and power dissipated are plotted against voltage in Figure 22, for four coils connected in series and parallel. At a particular voltage, one can observe and compare all the other parameters.

\section{Conclusion}

The paper proposed a modular design for the EPS and ACS of a microsatellite. The complete EPS is divided into three submodules, i.e., the SPM, PCM, and PDM. Every module has data and power interfaces which are standardized with specific number of input/output lines that meet the power and data requirement of microsatellite subsystems. COTS components were used for the subsystem implementation. The COTS components were selected on the basis of small dimension, minimum weight, and low power consumption. To avoid single component failure and increase the reliability, certain subsystems and components were made redundant in the design. To operate the solar panels at MPP and extract maximum power from them, a wide range highly efficient MPPT-based buck converter is designed and analyzed. Each solar panel has a separate MPPT unit with a $10 \mathrm{kHz}$ frequency gap to avoid synchronization between them. To protect the CMOS-based controllers from radiation, a latch-up protection system is designed and simulated. Different sensors such as current, temperature, and voltage are mounted at different locations on the respective modules to monitor and ensure proper operation of these units. For miniaturization purposes, an embedded magnetorquer is designed for the microsatellite which consumes reasonable power and generates the required magnetic moment. In the end, an EPS for the microsatellite is achieved which is fully modular, compact, redundant, and power efficient.

\section{Data Availability}

The data used to support the findings of this study are included within the article.

\section{Conflicts of Interest}

The authors announce that there is no conflict of interest concerning the publication of this article.

\section{References}

[1] C. Passerone, M. Tranchero, S. Speretta, L. Reyneri, C. Sansoe, and D. Del Corso, "Design solutions for a university nano-satellite," in 2008 IEEE Aerospace Conference, pp. 1-13, Big Sky, MT, USA, March 2008.

[2] J. C. de los Rios, D. Roascio, L. Reyneri et al., "ARAMIS: a fine-grained modular architecture for reconfigurable space missions," in 1st Conference on University Satellite Missions, Rome, January 2011.

[3] A. Ali, L. M. Reyneri, and M. Rizwan Mughal, Innovative Electric Power Supply System for Nano-Satellites, 64TH IAC, Beijing China, 2013. 
[4] D. Del Corso, C. Passerone, L. M. Reyneri et al., "Architecture of a small low-cost satellite," in 10th Euromicro Conference on Digital System Design Architectures, Methods and Tools (DSD 2007), Lubeck, Germany, August 2007.

[5] D. De Bruyn, "Power distribution and conditioning for a small student satellite, design of the NUTS backplane \& EPS module," in Master of Science in Engineering Cybernetics, Norwegian University of Science and Technology (NTNU), 2011.

[6] "Satellite mass categories," http://www.daviddarling.info/ encyclopedia/S/satellite_mass_categories.html.

[7] S. Dahbi, A. Aziz, S. Zouggar et al., "Power budget analysis for a LEO polar orbiting nano-satellite," in 2017 International Conference on Advanced Technologies for Signal and Image Processing (ATSIP), pp. 1-6, Fez, Morocco, May 2017.

[8] "Universities in space: seriously higher education," http:// spaceflight.com/universities-in-space-seriously-highereducation/.

[9] "World's largest database of nanosatellites, over 2150 nanosats and Cube Sats," https://www.nanosats.eu/.

[10] "Introduction to PNSS-P (1)," January 2014, http://suparco. gov.pk/pages/intro.asp,suparco.gov.pk/pages/presentationspdf/day-1/session-1/12B-III/4.pdf.

[11] C.-S. Sun and J.-C. Juang, "Design and implementation of a microsatellite electric power subsystem," Journal of Aeronautics, Astronautics and Aviation Series A, vol. 44, no. 2, pp. 67-74, 2012.

[12] S. Greenland, P. Mendham, M. Macdonald, C. McInnes, and C. Clark, "Implementation of a product-centric space system approach to nanosatellite systems design and deployment," in The 4S Symposium 2016, Valletta, Malta, May-June 2016.

[13] M. R. Mughal, J. C. De Los Rios, L. M. Reyneri, and A. Ali, "Scalable plug and play tiles for modular nano satellites," in 63rd International Astronautical Congress, Naples, Italy, October 2012.

[14] J. Esper, "Modular, adaptive, reconfigurable systems: technology for sustainable, reliable, effective, and affordable space exploration," AIP Conference Proceedings, vol. 746, pp. 10331043, 2005.

[15] K. B. Clark and C. Y. Baldwin, Design Rules. Vol. 1: The Power of Modularity, MIT Press, Cambridge, Massachusetts, 2000.

[16] P. M. Wegner, P. Blower, and J. Wilkenfeld, "Standard buses, modular buses, and plug-and-play buses; what is the difference and why does it matter?," Report No. A553345, 2008.

[17] J. S. O. Alvarado, J. S. R. Mora, and L. E. A. Pico, "Designs and implementations for CubeSat Colombia 1 satellite power module," International Journal of Applied Engineering Research, vol. 12, no. 18, pp. 7360-7371, 2017.

[18] B. Burger and R. Rüther, "Inverter sizing of grid-connected photovoltaic systems in the light of local solar resource distribution characteristics and temperature," Solar Energy, vol. 80, no. 1, pp. 32-45, 2006.

[19] M. Green, General Temperature Dependence of Solar Cell Performance and Implications for Device Modeling, John Wiley \& Sons, Ltd., 2003.

[20] W. J. Larson, Space Mission Analysis and Design, Third Edition, p. 217, 1999.

[21] P. C. M. De Carvalho, R. S. T. Pontes, D. S. Oliveira, D. B. Riffel, R. G. V. de Oliveira, and S. B. Mesquita, "Control method of a photovoltaic powered reverse osmosis plant without batteries based on maximum power point tracking," in 2004 IEEE/PES Transmision and Distribution Conference and Exposition: Latin America (IEEE Cat. No. 04EX956), pp. 137-142, Sao Paulo, Brazil, November 2004.

[22] M. Park and I. K. Yu, “A study on optimal voltage for MPPT obtained by surface temperature of solar cell," in 30th Annual Conference of IEEE Industrial Electronics Society, 2004. IECON 2004, pp. 2040-2045, Busan, South Korea, November 2004.

[23] T. Takashima, T. Tanaka, M. Amano, and Y. Ando, "Maximum output control of photovoltaic (PV) array," in Collection of Technical Papers. 35th Intersociety Energy Conversion Engineering Conference and Exhibit (IECEC) (Cat. No.00CH37022), pp. 380-383, Las Vegas, NV, USA, July 2000.

[24] N. Femia, D. Granozio, G. Petrone, G. Spagnuolo, and M. Vitelli, "Optimized one-cycle control in photovoltaic grid connected applications," IEEE Transactions on Aerospace and Electronic Systems, vol. 42, no. 3, pp. 954-972, 2006.

[25] W. Wu, N. Pongratananukul, W. Qiu, K. Rustom, T. Kasparis, and I. Batarseh, "DSP-based multiple peak power tracking for expandable power system," in Eighteenth Annual IEEE Applied Power Electronics Conference and Exposition, 2003. APEC '03, pp. 525-530, Miami Beach, FL, USA, February 2003.

[26] C. Hua and C. Shen, "Comparative study of peak power tracking techniques for solar storage system," in APEC '98 Thirteenth Annual Applied Power Electronics Conference and Exposition, pp. 679-685, Anaheim, CA, USA, February 1998.

[27] D. P. Hohm and M. E. Ropp, "Comparative study of maximum power point tracking algorithms using an experimental, programmable, maximum power point tracking test bed," Conference Record of the Twenty-Eighth IEEE Photovoltaic Specialists Conference - 2000 (Cat. No.00CH37036), 1699-1702, Anchorage, AK, USA, September 2000, 1699-1702.

[28] A. Dolara, R. Faranda, and S. Leva, "Energy comparison of seven MPPT techniques for PV systems," Journal of Electromagnetic Analysis and Applications, vol. 1, no. 3, pp. 152162, 2009.

[29] P. Ehrenfreund, B. H. Foing, and F. Salama, "Organics in space: results from space exposure platforms and nanosatellites," in IAU General Assembly, Meeting \#29, id. 2257551, American Astronomical Society, 2015.

[30] D. W. Hart, Power Electronics, mcgraw-Hill, New York, NY, USA, 2011, Print.

[31] N. Shams, F. Tanveer, and S. Ahmad, "Design and development of attitude control system (ACS) using COTS based components for small satellites," in 2008 2nd International Conference on Advances in Space Technologies, pp. 6-11, Islamabad, Pakistan, November 2008.

[32] V. Francois-Lavet, Study of Passive and Active Attitude Control Systems for the OUFTI Nanosatellites, University of Liege Faculty of Applied Sciences, 2009-2010.

[33] "SPENVIS: The Space Environment Information System," http://www.spenvis.oma.be. 


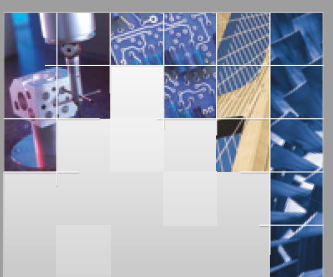

\section{Enfincering}
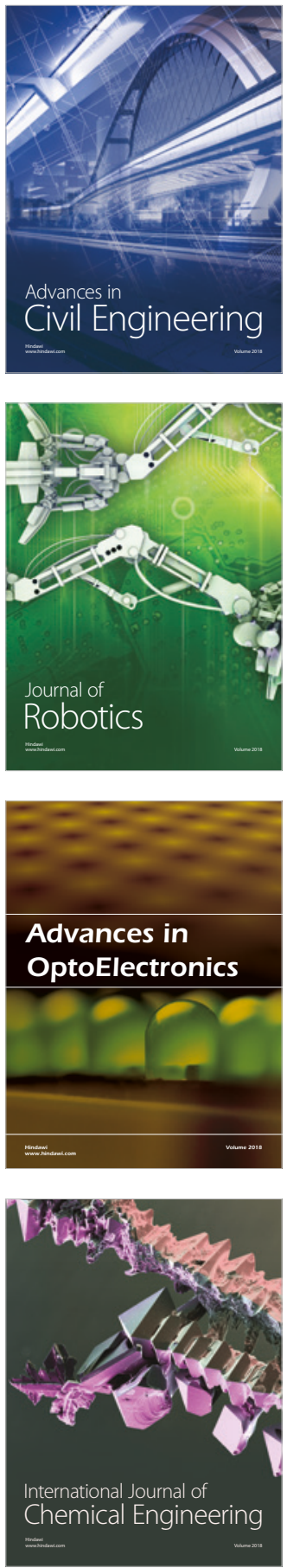

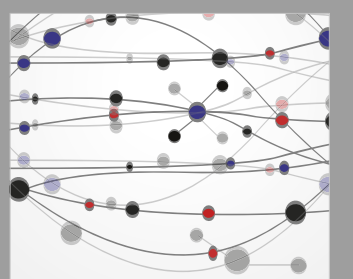

\section{Rotating \\ Machinery}

The Scientific World Journal

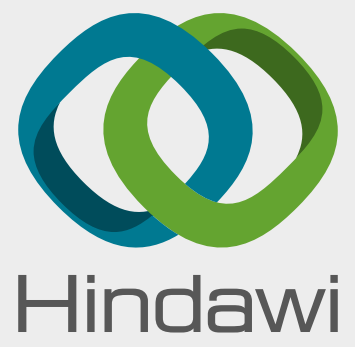

Submit your manuscripts at

www.hindawi.com
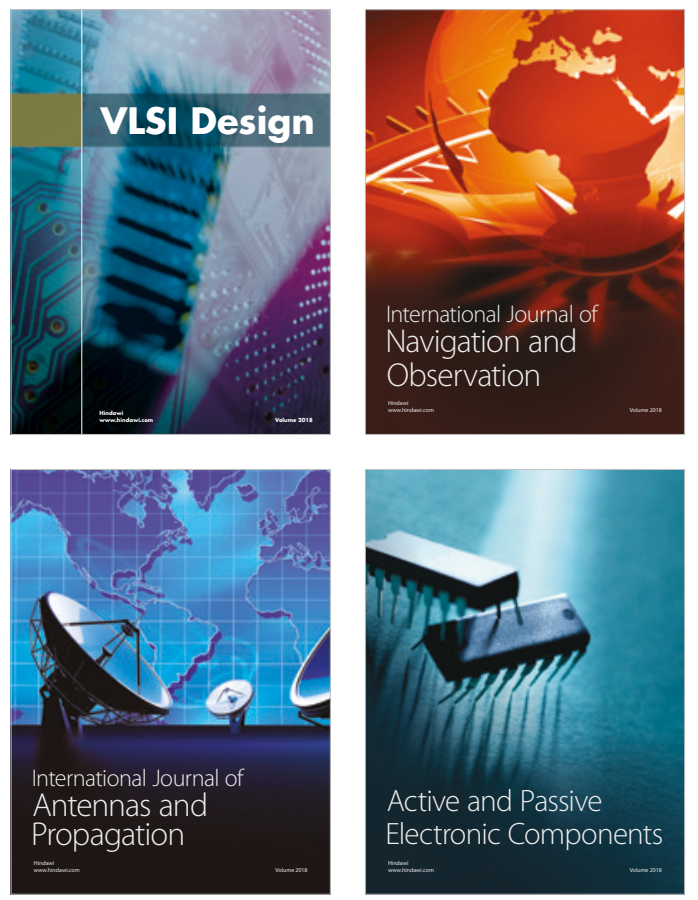
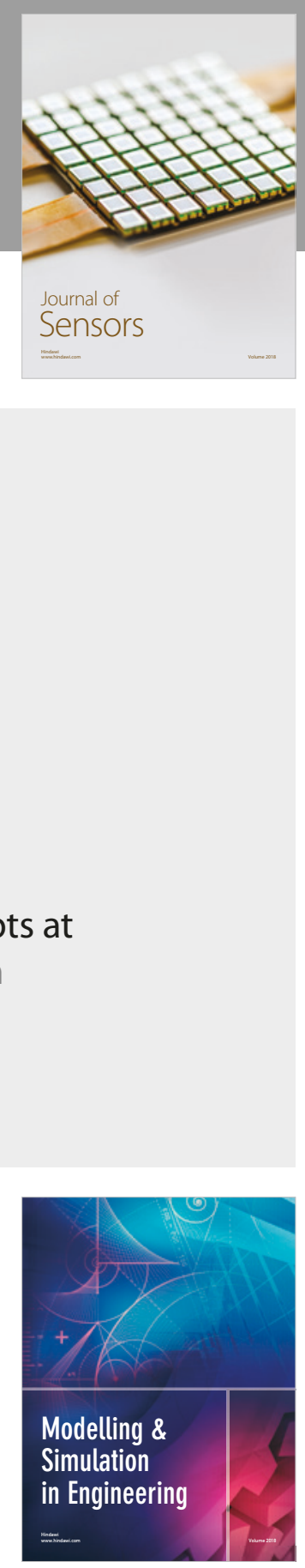

\section{Advances \\ Multimedia}
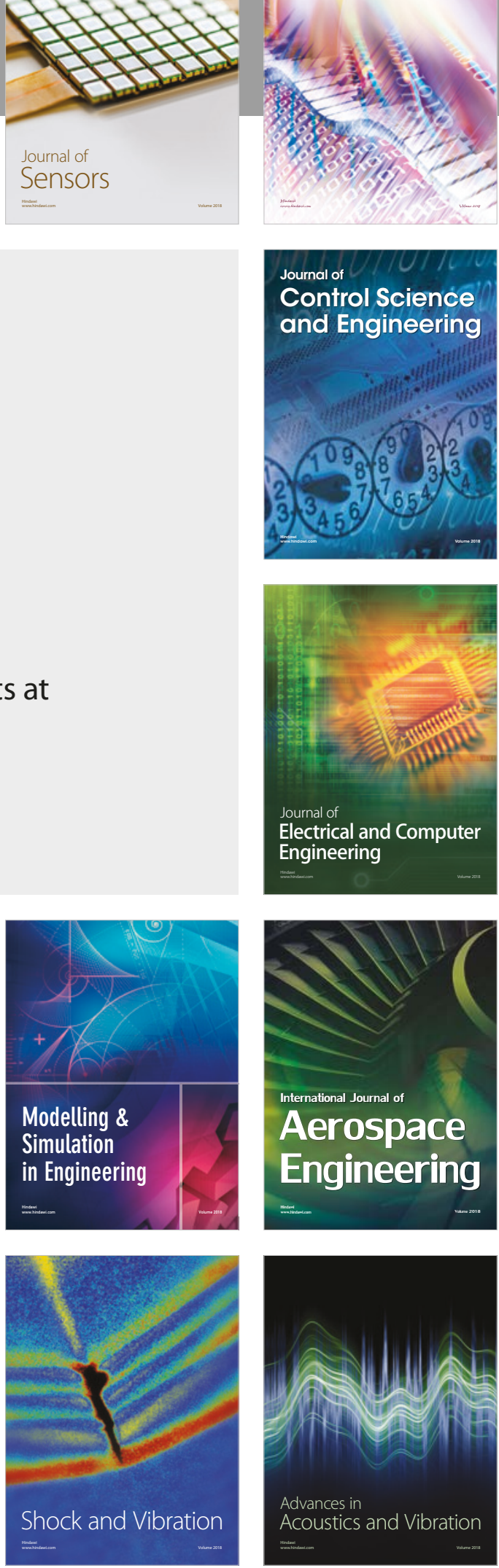